\title{
Determination of parameters of the bucket grab for excavation works
}

\author{
Ilya Tsipurskiy ${ }^{1, *}$ \\ ${ }^{1}$ Moscow State University of Civil Engineering, Yaroslavskoe shosse, 26, 129337, Moscow, Russia
}

\begin{abstract}
The construction of underground structures in an urban environment is accompanied by the solution of a number of complex geotechnical problems, including those associated with the creation of a deep underground cavity and a volume of hundreds of thousands of cubic meters. For soils of different categories, the difficulty of developing strata lying at different depths, sometimes up to 50 meters, is utilized by cable grabs. The article is devoted to the possibility of preliminary determination of parameters of the bucket grab for excavation works. For this purposes, existing empirical dependencies and the similarity method are used, which allow choosing optimal parameters of the bucket for specific ground conditions. Analytical calculations showed that the discrepancy between the values of the geometric parameters obtained by each of the methods lies in the range of up to $13 \%$, and the power parameters differ in the range up to $25 \%$. The use of the obtained values of the required parameters, with the indicated discrepancies in their magnitudes, allows to determine the optimum values of any parameter of the bucket for concrete excavations in the development of the underground space of cities.
\end{abstract}

\section{Introduction}

The life of modern society is possible only under certain conditions, characterized by a multitude of factors, both natural and anthropological. The problem of the rational use of the earth crust as a source of mineral resources and as an environment for human habitation and vital activity is at present one of the most important. Including diverse and multifaceted engineering activities to create transform and restore underground space.

Underground space is a space under the day surface, used to expand the habitat of citizens, to realize the priorities of ecological and economic well-being and sustainable development, to create conditions for people's life in extreme circumstances.

In all the major cities, both during the new construction and reconstruction of urban areas, active development of underground spaces is being carried out. The lack of free territories, the rapid growth of vehicles, the need to compact urban infrastructure require active involvement of underground space in the process of reconstruction of urban areas to accommodate transport and engineering systems. The need for active use of underground

*Corresponding author: cil@bk.ru 
spaces is due to a number of important circumstances and is obvious [1]. Depending on the specific situations of the places of production of construction works, ground conditions, density of construction, traditional construction technology provides for the creation of excavations in the form of excavations and embankments, more often with external excavation of soil. The erection of structures buried in the ground requires a huge amount of excavation work on the digging of deep excavations and often in conditions with a layered arrangement of soils of different design difficulties. The construction of urban underground structures in open excavations implies the erection of underground structures in a previously opened pit with backfilling with its soil and restoration of engineering improvement of the territory.

All these types of excavation when creating an underground space require specialized equipment.

\section{Materials and methods}

Mechanization of the process of different types of work in the practice of active development of underground space is carried out by different groups of machines. Classification of these machines is carried out for technological (production) purposes. The general arrangement and principle of operation of the main types of machines for the arrangement of nature, the scope of their application, advantages and disadvantages, the necessary set of technical indicators and methods for assessing their technological capabilities are sufficiently widely covered in the technical literature $[2,3]$.

The necessity of using special equipment and equipment arises in all spheres of construction industry and real estate, without exception: the erection of various engineering structures, the carrying out of protective and restorative measures of a building nature (remediation, shore fortification, canals, roads), etc.

To develop soils during the development of underground space, excavators of various types are used: one-bucket (with direct and reverse shovel, dragline, grapple), bulldozers and multi-bucket trenchers (chain and rotor) $[4,5]$.

The most large-scale and voluminous in the construction of underground structures are excavation works, the essence of which is to create excavations and embankments. For this purpose, by 2004, there were 63280 single-bucket excavators, 18600 scrapers, 62,000 bulldozers, about 90 trench excavators and many thousands of other machines on the construction sites of our country [6]. Their application directs specialist in the development of underground space to the greatest possible preservation of the same conditions that took place in the developed territory before the arrival of people on it. So, for example, any of the above-mentioned excavation machines and, in particular, an excavator with a working equipment of a grab bucket can be used to create a pit (pit or canal) (Fig.1).The grab bucket is used for digging deep pits, wells, as well as digging trenches underwater at great depths.

In the zone of underground space development, the ground is developed by a bucket of a grapple when erecting underground structures by the pit method, by pressing the lowered well (at a depth of up to $50 \mathrm{~m}$ ), by designing the face for the constructed structure by the "wall in the ground" method, by erecting structures and "from above down".

In all cases, engineering and geological conditions, depending on the depth of the face, change representing soils of different categories of developmental difficulties. The use of clamshell buckets with the corresponding kinematic and power parameters ensures the digging of the soil in different categories of development difficulties. 


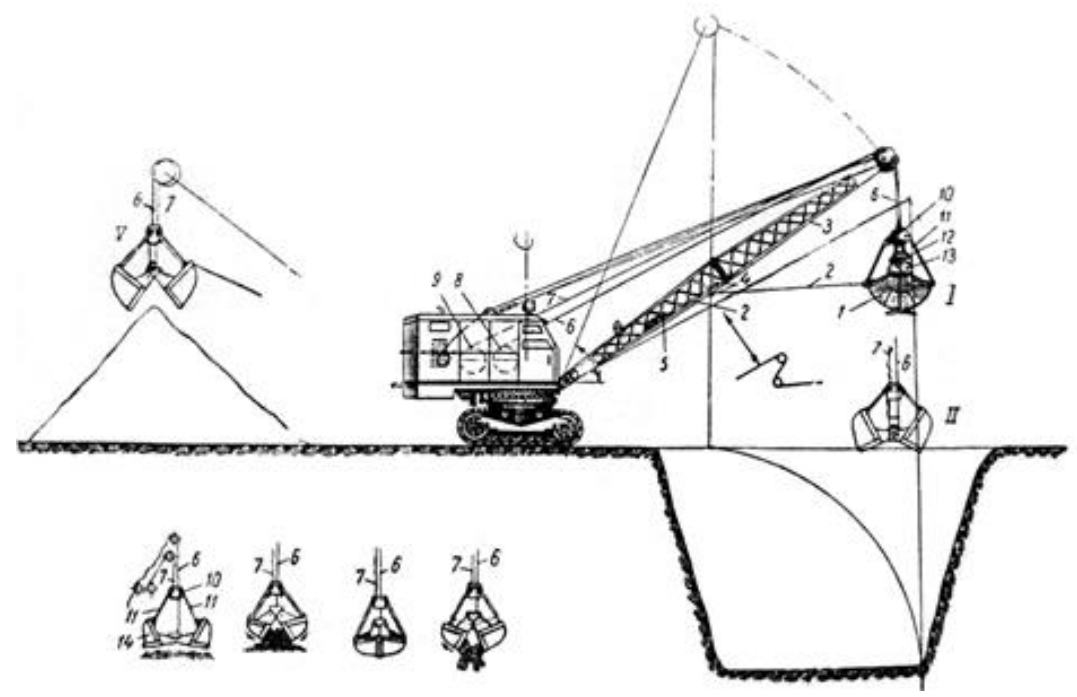

Fig. 1. Formation of excavation excavator with bucket of grapple.

The working equipment of the excavator with a bucket of a grapple includes an elongated lattice boom 3, a boom lifting chain 17, two jaw clamshell bucket 1, lifting (supporting) 7 and closing 6 ropes. To prevent the bucket from swinging and twisting, a rope 2 is attached, fixed at one end to it, and the other, by bending block 4, is fastened to the pulling device 5 . The lifting rope 7 is fixed to the upper head 10 (inside it there are blocks of the upper cage of the pulley block) to which the jaws 14 of the bucket shape are connected by means of the rods 11 . The inner ends of the jaws are connected to each other by a hinge 13 on which the lower head of the grapple 12 sits (inside it there are blocks of the lower cage of the pulley), with a closing rope attached to it. 6 . To increase the digging force that introduces the edges of the bucket jaws into the developed material, are stored between the upper and lower heads of the grapple in the form of a pulley of this or that multiplicity. The multiplicity of the pulley block depends on the kind and strength of the developed soil - the category of development difficulties. In rope grabs, the driving links are: a locking rope 8, a lifting rope (drum) 9, and a rope lifting drum 15 that surrounds the block of a two-legged column. They are located on the excavator winches and are connected to the remaining links by a flexible link - ropes 6 and 7 , head blocks 18 of the boom. In rope and non-pressure driven grabs, the introduction of jaws into the material and the scooping process is carried out by the force of gravity (weight) of the grapple and forces on the cutting edges of the bucket [7]. The main advantage of a rope excavator with a grab is the technology of the bucket of this type, which develops (digging) the ground exactly under the head of the boom. The ground can be unloaded at high altitude, as the grapple boom can be installed at an angle of 60 to 70 degrees. to the horizon, which is of great importance in the shortage of free territories and space [8,9]. The maximum digging depth of an excavator with a grab is determined by the length of the ropes and the allowable angle of slope in the given soil in accordance with the stability conditions. These options allow you to select the parameters of the bucket for those that optimize the mechanization of excavation at a particular facility with the established category of difficulty in working out the soil, the appropriate size (for example, in depth) and volumes.

\section{Results}


To determine the parameters of the bucket digging bucket in the technical literature are various recommendations, in particular, based on empirical relationships $[10,11]$. In order to establish the reliability of these dependences, computational and experimental studies were carried out using the theory of similarity and modeling methods of digging work tools [12]. The existing empirical formulas were summarized in a single table [13]. To these tabulated data, the dependencies recommended by us were added, which determine the values of the power and energy parameters characterizing the digging process. Partially these generalized data are given in the following table 1 below. These parameters determined the parameters of buckets of any capacity.

Table 1. Empirical dependencies for determining the parameters of the grab bucket.

\begin{tabular}{|c|c|c|c|c|c|}
\hline $\begin{array}{l}\text { No. } \\
\text { pp. }\end{array}$ & Parameter name & 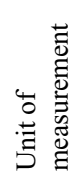 & 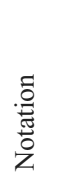 & $\begin{array}{l}\text { The empirical } \\
\text { formula }\end{array}$ & 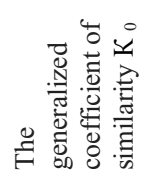 \\
\hline 1 & Grapple bucket capacity & $\mathrm{m}^{3}$ & $\mathrm{q}$ & - & $\left(\kappa_{1}\right)^{3}$ \\
\hline 2 & Grab bucket weight & кг & Gгр & $\kappa_{\text {гр }} \cdot \mathrm{q}$ & $\left(K_{1}\right)^{3}$ \\
\hline 3 & Weight (gravity) bucket & кN & G & 9,81· Сгр & $\left(K_{1}\right)^{3}$ \\
\hline 4 & Thickness of sheet steel & $\mathrm{m}$ & $\mathrm{S}$ & $0,01 \cdot \sqrt[3]{q}$ & $\left(K_{1}\right)^{1}$ \\
\hline 5 & Inner width of jaw & $\mathrm{m}$ & B & $1,1 \cdot \sqrt[3]{q}$ & $\left(\kappa_{1}\right)^{1}$ \\
\hline 6 & Radius of curvature of jaw & $\mathrm{m}$ & $\mathrm{r}$ & $1,25 \cdot \sqrt[3]{q}$ & $\left(K_{1}\right)^{1}$ \\
\hline 7 & $\begin{array}{l}\text { Radius of the probable trajectory of } \\
\text { the jaw edges }\end{array}$ & $\mathrm{m}$ & $\mathrm{R}$ & $1,4 \cdot \sqrt[3]{q}$ & $\left(K_{1}\right)^{1}$ \\
\hline 8 & Thrust Length & $\mathrm{m}$ & 1 & $1,9 \cdot \sqrt[3]{q}$ & $\left(K_{1}\right)^{1}$ \\
\hline 9 & $\begin{array}{l}\text { The length of the maximum opening } \\
\text { of the jaws }\end{array}$ & $\mathrm{m}$ & $\mathrm{L}$ & $2,45 \cdot \sqrt[3]{q}$ & $\left(K_{1}\right)^{1}$ \\
\hline 10 & $\begin{array}{l}\text { The area of the ground covered by the } \\
\text { open jaws of the grapple }\end{array}$ & $\mathrm{m}^{3}$ & $\mathrm{~F}$ & $2,7 \cdot \sqrt[3]{q^{2}}$ & $\left(K_{1}\right)^{2}$ \\
\hline 11 & $\begin{array}{c}\text { Imitational volume of a parabolic } \\
\text { segment }\end{array}$ & $\mathrm{m}^{3}$ & $\mathrm{q}_{\mathrm{c}}$ & $1,8 \cdot \sqrt[3]{q^{2}} \cdot \mathrm{C}_{\max }$ & $\left(K_{1}\right)^{3}$ \\
\hline 12 & $\begin{array}{l}\text { The greatest thickness of chips at the } \\
\text { time of jaw closure }\end{array}$ & $\mathrm{m}$ & $\mathrm{C}_{\max }$ & $0,56 \cdot \sqrt[3]{q}$ & $\left(K_{1}\right)^{1}$ \\
\hline 13 & $\begin{array}{l}\text { The largest cross-section of ground } \\
\text { shavings }\end{array}$ & $\mathrm{m}^{2}$ & Fп & $0,62 \cdot \sqrt[3]{q^{2}}$ & $\left(K_{1}\right)^{2}$ \\
\hline 14 & $\begin{array}{l}\text { The value of } \mathrm{P}_{02} \text { at the moment of } \\
\text { jaw closure }\end{array}$ & кN & $\mathrm{P}_{02}$ & $\frac{9,81\left(\mathrm{G}_{\mathrm{rp}}+\mathrm{q}_{\mathrm{c}} \cdot \gamma_{\mathrm{M}}\right)}{2}$ & $\left(K_{1}\right)^{3}$ \\
\hline 15 & $\begin{array}{c}\text { The value of } \mathrm{P}_{01} \text { at the moment of } \\
\text { jaw closure }\end{array}$ & кN & $\mathrm{P}_{01}$ & $2 \mathrm{P}_{02}$ & $\left(K_{1}\right)^{3}$ \\
\hline 16 & Specific resistance of soil to digging & кРа & $\mathrm{k}_{1}$ & $\mathrm{P}_{01} / \mathrm{F}_{\mathrm{n}}$ & $\left(K_{1}\right)^{3}$ \\
\hline
\end{tabular}




\section{Discussion}

In parallel, to determine the size of the bucket and the resistance to digging buckets of different capacities on the soils of different design difficulties, a method was used to simulate the parameters of the bucket.

Earlier it was established [14] that, depending on the capacity, or rather on the weight of the bucket, it can develop soils of different difficulty categories. Therefore, the proposed range of twelve grab buckets with capacity from 0.5 to 6.0 cubic meters was divided into four groups with an interval of $0.5 \mathrm{~m} 3$. The composition of the buckets of each group hypothetically capable of developing soils with a corresponding specific soil resistance of digging $-\mathrm{K}_{1}(\mathrm{kPa})$ is presented in the table.

Table. 2. A number of buckets for modeling their parameters.

\begin{tabular}{|c|c|c|c|c|c|c|c|c|c|c|c|c|}
\hline \multirow{2}{*}{$\begin{array}{l}\text { Group } \\
\text { number } \\
\begin{array}{l}\text { Bucket capa- } \\
\text { city } \mathrm{q}_{\mathrm{n}}, \mathrm{m}^{3}\end{array}\end{array}$} & \multicolumn{3}{|c|}{$\begin{array}{c}\text { The first, } \\
\mathrm{K}_{1}=30-120 \kappa \mathrm{Pa}\end{array}$} & \multicolumn{3}{|c|}{$\begin{array}{l}\text { The second, } \\
\mathrm{K}_{1}=120-200 \kappa \mathrm{Pa}\end{array}$} & \multicolumn{3}{|c|}{$\begin{array}{l}\text { The third, } \\
\mathrm{K}_{1}=180-300 \kappa \mathrm{Pa}\end{array}$} & \multicolumn{3}{|c|}{$\begin{array}{l}\text { Fourth, } \\
\mathrm{K}_{1}=250-420 \kappa \mathrm{Pa}\end{array}$} \\
\hline & 0,5 & 1,0 & 1,5 & 2,0 & 2,5 & 3,0 & 3,5 & 4,0 & 4,5 & 5,0 & 5,5 & 6,0 \\
\hline $\begin{array}{l}\text { The similarity } \\
\text { coefficient }\end{array}$ & 3,68 & 4,64 & 5,3 & 5,85 & 6,3 & 6,69 & 7,05 & 7,37 & 7,66 & 7,94 & 8,19 & 8,43 \\
\hline
\end{tabular}

Presumably, each bucket from these groups can dig soils of a corresponding category of developmental difficulty. An analysis of the results obtained earlier [15] showed that the entire sample range of existing replacement bucket grabs on the excavator, by the criterion of soil resistivity, digging can theoretically dig the soils up to the second (II) category of development difficulty. Removable grapple buckets (from 3.5 to $4.5 \mathrm{~m}^{3}$.) Can practically dig the ground, including the third (III) category of development difficulty. Digging the heavier soils with a rope grab of larger capacity requires disproportionately heavy ladles, which in operating conditions is not rational. This circumstance should be taken into account in the transformation and restoration of natural components. Digging of deep excavations on soils of the fourth and higher categories of the development difficulty should be carried out with excavators with the "pressure grab" equipment. In studies as a laboratory model, empirical dependencies of two jaw clamshells with a capacity of $\mathrm{q}_{\mathrm{m}}=0.01 \mathrm{~m}^{3}$ (10 liters) were recommended in the technical literature. This laboratory ladle (Fig. 2) was the basic model in establishing the similarity coefficients $\mathrm{K}_{1}$ (linear scale) for determining the parameters of each of the twelve buckets (hypothetically actual) with the corresponding capacity $\mathrm{q}_{\mathrm{n}}$, as follows:

$$
K_{1}=\sqrt[3]{q_{n} / q_{m}}
$$

The parameters of each bucket from the hypothetical series were determined by two methods: Pe.

The first - based on empirical relationships set the value of the corresponding parameter

The second, using the theory of similarity using the generalized modeling coefficient, set the value of the corresponding parameter Pm. The definition of the latter (Pe ) was realized according to the recommendations of the source [10,11].

The definition of the latter $(\mathrm{Pn})$ was realized according to the recommendations of the source [12] by establishing a generalized coefficient of similarity $K 0$ for each of the determined parameters of the full bucket bucket. The generalized coefficient is a power-law dependence of the linear coefficient Kl. For linear, angular and specific parameters, the degree value is 1-unit. For areas and forces of resistance, the degree value is equal to 2-two, and for volume, weight and energy indicators, the degree value is 3 -three (see Table 1). 


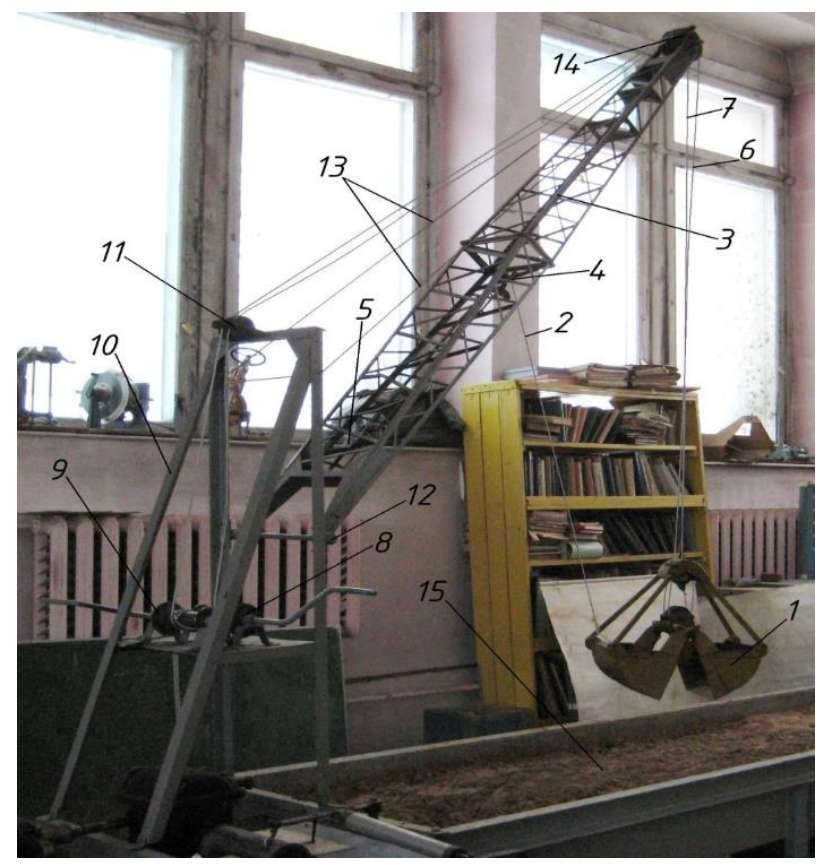

Fig. 2. Stand with model of grapple laboratory bucket. Where: 1-clamshell bucket; 2-pull rope; 3arrow; 4- block of the pulling rope; 5- pulling device; 6 - closing rope; 7- lifting (supporting) rope; 8a locking rope of a locking rope with a manual drive; 9- a rope of a lifting rope with a manual drive; 10-a two-legged stance; 11 - blocks on a two-legged counter; 12 - the fifth of the arrow; 13 - lifting rope; 14-head boom blocks; 15 - ground channel.

\section{Conclusion}

Comparison of the values of the values of the same parameter obtained for each of the calculation methods, i.e. comparison Pe and Pm, was conducted by methods of mathematical statistics. The discrepancy between the results for individual parameters ranged from 13 to 25 percent. At the same time, part of the parameters with the greatest discrepancy in results fall on the energy indicators, which is confirmed by the previously established fact of the irrationality of digging heavy soils with clamshell buckets of large capacity. The studies also confirmed the reliability of the majority of empirical dependencies for determining the parameters of grapple buckets.

The choice of working ladles for these parameters and their application allows to optimize the indices of the formation process of the excavation at different depth levels in soils of different categories of development difficulties.

\section{References}

1. Guidelines for the integrated development of the underground space of large cities (RAASN, Moscow, 2004)

2. V.L. Belyaev, V.B. Belyaev, Messenger MGSU 2, 7-12 (2014)

3. P.P. Ipatov, E.Yu. Pasechnik, Machinery and equipment for environmental management and water use (Publishing house of Tomsk Polytechnic University, Tomsk, 2012) 
4. B.V. Krasnovshek, Technology and mechanization of construction processes (UMK, FEFU, 2015)

5. I.L. Tsipursky, Mechanization of Construction 11(857), 7-8 (2015)

6. A.B. Ponomarev, Yu.L. Vinnikov, Underground construction (Publishing house of Perm. nat. Issled. polytech. University, Perm, 2014)

7. I.L. Tsipurskiy, Excavator with working equipment of dragline and grab (MGSU, Moscow, 2011)

8. D.S. Konyukhov, Construction of urban underground structures (Publishing House Architecture-S, Moscow, 2005)

9. V.I. Telichenko, Modern technologies of integrated development of underground space megacities (Publisher ASV, Moscow, 2010)

10. V.I. Balovnev, Optimization and selection of innovative systems and processes. Transport- technological machines (Tehpoligratsentr, Moscow, 2014)

11. E.M. Kudryavtsev, Construction machinery and equipment (Publisher ASV, Moscow, 2012)

12. V.I. Balovnev, Modeling the processes of interaction with the working environment. Bodiesof road-building machines (Mashinostroye, Moscow, 1994)

13. I.L. Tsipurskiy, Settings digging and recruitment earthmoving machines (Publisher ASV, Moscow, 2016)

14. I.L. Tsipursky, Mechanization of construction 4, 20-23 (2010)

15. I.L. Tsipursky, Construction and Road machines 9, 17-19 (2010) 